Original Article

\title{
Influence of pitching grip on shoulder and elbow injuries in junior baseball players, focusing on hand length and the metacarpophalangeal joint angle
}

\author{
Naoki Tanaka, RPT, MS ${ }^{1,2)^{*}}$, Yasutomo Sakai, RPT, PhD ${ }^{2)}$, Wataru Iwamoto, MD $^{3)}$, \\ KoJi WaGatsuma, RPT, MS ${ }^{4}$ \\ 1) Faculty of Health Care and Medical Sports, Teikyo Heisei University: 4-1 Uruidominami, Ichihara, \\ Chiba 290-0193, Japan \\ 2) Graduate School of Health Science, Teikyo Heisei University, Japan \\ 3) Department of Sports Medicine, Edogawa Hospital, Japan \\ 4) Department of Sports Rehabilitation, Edogawa Hospital, Japan
}

\begin{abstract}
Purpose] We investigated the relationship of pitching grip with hand length and index finger metacarpophalangeal joint angle. [Participants and Methods] A total of 650 junior baseball players divided into two groups according to whether they experienced shoulder or elbow pain were divided into two groups based on their pitching grip, i.e., those who held the ball with the ulnar side of the thumb and those who held it with the finger pad of the thumb. The metacarpophalangeal joint angle was measured while the participants held a ball. [Results] The average hand length was $16.3 \pm 1.4 \mathrm{~cm}$ for those holding the ball with the ulnar side of the thumb and $15.8 \pm 1.2 \mathrm{~cm}$ for those holding it with the finger pad of the thumb. Hand length and metacarpophalangeal angle were significantly greater in the group using the ulnar side of the thumb. The two groups showed no significant differences in the distribution of grip type or history of shoulder/elbow pain. The index finger metacarpophalangeal angle and shoulder/elbow pain were significantly lower in the pain group. [Conclusion] With respect to the pitching grip for junior baseball players, we recommend a slightly flexed rather than extended position with the metacarpophalangeal angle.

Key words: Junior baseball, Pitching grips, Throwing injury
\end{abstract}

(This article was submitted Apr. 19, 2021, and was accepted Jun. 6, 2021)

\section{INTRODUCTION}

Throwing injuries in junior baseball players typically manifest as Little Leaguer's shoulder, humeral medial epicondylar lesions, and osteochondritis dissecans of the capitellum. They can be caused by traction stress, compression stress, and blood flow disorders on the growing cartilage plate ${ }^{1-3}$. It has been reported that $30-58 \%$ of junior baseball players experience elbow pain during their growing up age ${ }^{4,5)}$. The prevention and treatment of these injuries requires rest and external fixation as well as improvements in the function of the hip joint, trunk, and scapula girdle ${ }^{6}$. When throwing, energy is transferred from the lower limbs to the trunk and upper extremities, which delivers energy to the ball using a total of 13 degrees of freedom from the trunk to the wrist joint ${ }^{7}{ }^{8)}$. The fingers are the final effectors in the throwing motion. The index and middle finger exert their maximum strength $30-50 \mathrm{~ms}$ before and immediately before releasing the ball. The strength of the ring finger and thumb are negligible ${ }^{9)}$. It is recommended that the pitcher grip the lower surface of the ball with the other side of the index finger and the middle finger on the measure side of the thumb to enhance performance and prevent injuries ${ }^{10)}$.

*Corresponding author. Naoki Tanaka (E-mail: n.tanaka@thu.ac.jp)

(C2021 The Society of Physical Therapy Science. Published by IPEC Inc.

(c) (1) $\odot$ This is an open-access article distributed under the terms of the Creative Commons Attribution Non-Commercial No Deriva-

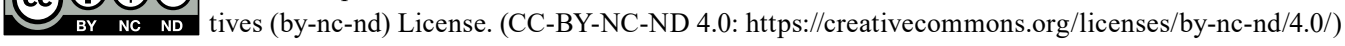


However, a junior player, a female baseball player, or a softball player using a large ball cannot wrap their hand around the ball according to this recommendation. Therefore, each finger must be in the extended position and the thumb is forced to grip the side of the ball. Non-sports studies have reported that the position of the thumb changes the muscle activity of the flexor and extensor muscles of the forearm in simple grasping movements ${ }^{11)}$. Different methods of holding the ball in baseball are affected by hand length and ball size and may influence the position of the thumb and the metacarpophalangeal joint (MP) angle. However, the techniques used to grip the ball by a small player, such as a junior baseball player, have not been studied. The relationship between pitching grip and throwing injury has been judged only by the position of the thumb, but it is necessary to consider how to grip the ball by adding the MP joint angle. The purpose of this study was to clarify the relationship between pitching grip and pitching injury with hand length, thumb position, and MP joint angle.

\section{PARTICIPANTS AND METHODS}

The participants were 650 junior baseball players (mean age, $10.4 \pm 0.9$ years; mean height, $142.9 \pm 7.7 \mathrm{~cm}$; mean weight, $37.0 \pm 7.7 \mathrm{~kg}$ ). The participants and their parents were informed in advance of the purpose of this study in accordance with the Declaration of Helsinki. Prior to the experiment, informed consent was given and verbal and written consent was obtained from the subjects. The resulting data was securely stored under an encrypted name to protect the participants privacy. Ethical approval for this study was obtained from the ethics review committee of Teikyo Heisei University (approval code: 2019126).

The following variables were tested: (1) shoulder or elbow pain experienced during the past year (determined with a questionnaire; classified into "pain" and "no pain" group), (2) hand length, (3) grip type classification (thumb position), and (4) index finger MP angle when holding the ball.

The hand length was measured on the throwing hand. The distance from the point between the radial and ulnar processes to the tip of the middle finger was measured using a tape measure. The players gripped and held the ball while imitating a pitching motion several times in order to reproduce ball grips used during regular pitching. We divided the players into two groups based on their grip style. One group had the thumb flexed and positioned on the ulnar side on the other side of the ball from the ulnar side of the index finger (flexed thumb group), and the other group had the thumb extended and held the ball by the pad of the thumb and positioned on the radial side of the index finger (extended thumb group) (Fig. 1).

We used an All Japan Baseball League Official C class ball (diameter, $68 \mathrm{~mm}$; average weight, $128 \mathrm{~g}$ ). The index finger MP angle was measured from the heel side using a finger goniometer from the radial side while the player held the ball. The flexion direction was noted as $(+)$ and the extension direction as (-). The minimum unit of angle measurement was $2^{\circ}$ (Fig. 2). The hand length between the flexed thumb group and extended thumb group and the MP angle between the pain group and no pain group were compared using an independent t-test. The $\chi^{2}$ test was used to compare the rates of pain experienced by each grip group and calculated the relationship with types of grip and history of pain using phi coefficient. R for Windows (version 2.13.0) was used for statistical processing, and the statistical significance level was $5 \%$.

\section{RESULTS}

The mean hand length was $16.3 \pm 1.4 \mathrm{~cm}$ in the flexed thumb group $(\mathrm{n}=214)$ and $15.8 \pm 1.2 \mathrm{~cm}$ in the extended thumb group $(n=436)$, which indicates that the mean hand length was significantly higher in the flexed thumb group. The index finger MP angle was significantly higher in the extended thumb group, with an average of $0.7 \pm 5.7^{\circ}$ in the flexed thumb group and $5.2 \pm 5.5^{\circ}$ in the extended thumb group (Table 1). The results of the $\chi^{2}$ test showed a significant difference in type of grip and history of pain $(\mathrm{p}<0.05)$, but the phi coefficient was 0.12 and the two items were not related (Table 2$)$. The index
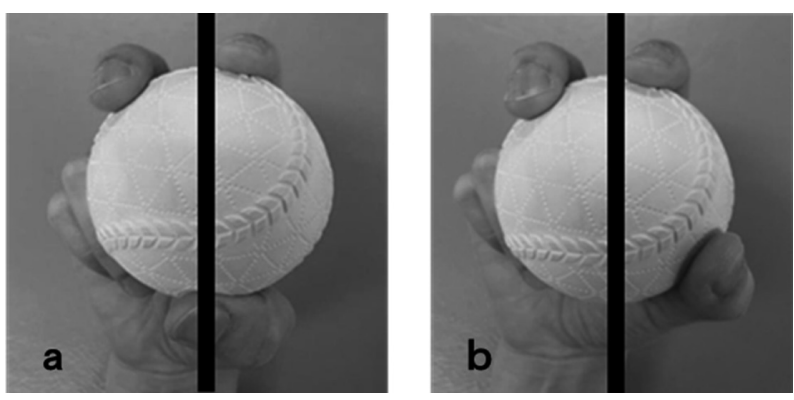

Fig. 1. Types of grips.

a) Flexed thumb group.

b) Extended thumb group.
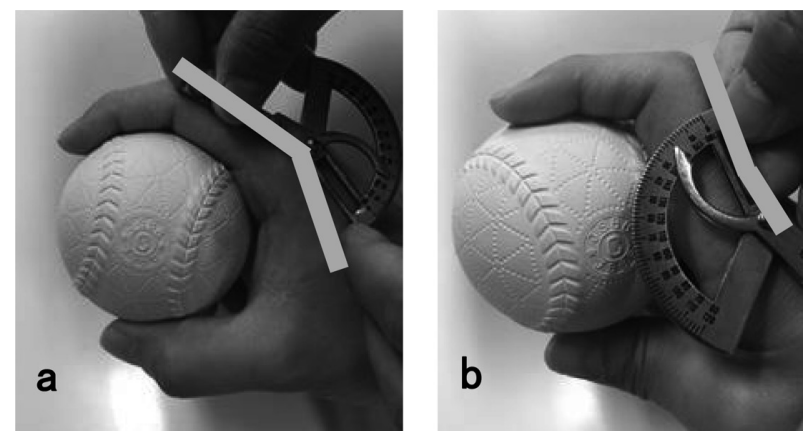

Fig. 2. The index finger MP angle measurement.

a) Flexion (+).

b) Extension (-). 
finger MP angle and shoulder and elbow pain were significantly lower in the pain group $(\mathrm{n}=281)$ than in the no pain group $(\mathrm{n}=369)(\mathrm{p}<0.05)($ Table 3$)$.

\section{DISCUSSION}

It is imperative to prevent injuries in junior players because they can result in significant immediate and long-term consequences, including risk of future injuries, cognitive deficits, and other health burdens ${ }^{12}$. The majority of baseball elbow injuries are non-contact injuries to the dominant arm resulting from repetitive pitching ${ }^{13}{ }^{14}$ ). We thought that we should also pursue information about more detailed functions involved in pitching such as those of the fingers.

In this study, the number of junior baseball players experiencing shoulder or elbow pain was investigated focusing on hand length, grip style and MP angle. The results showed that $43.2 \%$ of the junior baseball players had experienced shoulder or elbow pain in the previous year. The shoulder and elbow joint torque was largest during acceleration in the young male baseball players, which is similar to adult players, and the maximum valgus torque was $18 \mathrm{Nm}$ on average for the junior baseball players. A limit on the number of balls and innings pitched has been proposed for junior baseball players in order to prevent injuries ${ }^{15}$. Effective multilateral measures are needed in the future to help achieve this goal.

In this study on junior baseball players, hand length was significantly longer in the flexed thumb group which was evidence that this group selected the flexed thumb grip more often. With regard to hand length and index finger MP angle, the extended thumb grip uses the radial abduction position, while the flexed thumb grip uses the ulnar adduction position (the opposing position). Although the flexed thumb position has been recommended for gripping the ball, in this study, classification using only the thumb position did not show a clear relationship with throwing injury. Regarding the relationship between shoulder or elbow pain and the index finger MP joint angle, the index finger MP joint had a small angle (extended position) in the pain group and the index finger MP joint had a large angle (flexed position). I expected that there would be a difference in muscle activity between gripping and releasing the ball in the MP joint flexed position and MP joint extended. The throwing motion mainly uses the flexor-pronator mass, including the flexor digitorum profundus and flexor digitorum superficialis, flexor carpi ulnaris, pronator teres, and intrinsic hand muscles (lumbrical muscle). It is possible that throwing at MP joint

Table 1. Ball grip groups with hand length and index finger MP angle

\begin{tabular}{lccc}
\hline & $\begin{array}{c}\text { Flexed thumb group } \\
(\mathrm{n}=214)\end{array}$ & $\begin{array}{c}\text { Extended thumb group } \\
(\mathrm{n}=436)\end{array}$ & p-value \\
\hline Hand length $(\mathrm{cm})$ & $16.3 \pm 4.5$ & $15.8 \pm 4.2$ & $<0.05$ \\
Index finger MP angle $\left(^{\circ}\right)$ & $0.7 \pm 5.7$ & $5.2 \pm 5.5$ & $<0.05$ \\
\hline Mean \pm SD. & & &
\end{tabular}

Table 2. Type of grip and history (past 1 year) of shoulder and elbow pain

\begin{tabular}{lcc}
\hline & $\begin{array}{c}\text { Flexed thumb group } \\
(\mathrm{n}=214)\end{array}$ & $\begin{array}{c}\text { Extended thumb group } \\
(\mathrm{n}=436)\end{array}$ \\
\hline No pain group & 103 & 266 \\
& $(-3.1)$ & $(3.1)$ \\
Pain group & 111 & 170 \\
& $(3.1)$ & $(-3.1)$ \\
\hline
\end{tabular}

Adjusted standardized residuals appear in parentheses below group frequencies.

\begin{tabular}{lccc}
$\chi^{2}$ tests & & & \\
\hline$\chi^{2}$ value & Value & df & $p$ \\
Phi coefficient & 9.18 & 1 & $<0.05$ \\
\hline
\end{tabular}

Table 3. Index finger MP angle and history (past 1 year) of shoulder and elbow pain

\begin{tabular}{lccc}
\hline & $\begin{array}{c}\text { No pain group } \\
(\mathrm{n}=369)\end{array}$ & $\begin{array}{c}\text { Pain group } \\
(\mathrm{n}=281)\end{array}$ & $\mathrm{p}$-value \\
\hline Index finger MP angle $\left(^{\circ}\right)$ & $5.2 \pm 4.9$ & $1.3 \pm 4.2$ & $<0.05$ \\
\hline
\end{tabular}

Mean \pm SD. 
extended position reduces the activity of the lumbrical muscles, causing the activity of the flexor digitorum profundus and flexor digitorum superficialis to increase, the traction stress of the medial epicondyles to increase, and the mobility of the forearm and wrist joint to decrease. We suggest that flex the MP joint slightly to hold the ball to prevent pitching injuries for junior baseball players.

The limitations of this study are that the effect of other body parts that are in contact with the ball, such as the ring finger and palm surface, could not be taken into consideration in reference to grip style, and the MP joint angle measurement was performed while the player was holding the ball. We need to investigate the pitching grip in detail using motion analysis and EMG analysis.

\section{Conflict of interest}

There are no potential conflicts of interest to disclose.

\section{REFERENCES}

1) Kanematsu Y, Matsuura T, Kashiwaguchi S, et al.: Epidemiology of shoulder injuries in young baseball players and grading of radiologic findings of Little Leaguer's shoulder. J Med Invest, 2015, 62: 123-125. [Medline] [CrossRef]

2) Brogdon BG, Crow NE: Little leaguer's elbow. Am J Roentgenol Radium Ther Nucl Med, 1960, 83: 671-675. [Medline]

3) Pappas AM: Elbow problems associated with baseball during childhood and adolescence. Clin Orthop Relat Res, 1982, (164): 30-41. [Medline]

4) Takagishi K, Matsuura T, Masatomi T, et al.: Shoulder and elbow pain in elementary school baseball players: the results from a nation-wide survey in Japan. J Orthop Sci, 2017, 22: 682-686. [Medline] [CrossRef]

5) Grana WA, Rashkin A: Pitcher's elbow in adolescents. Am J Sports Med, 1980, 8: 333-336. [Medline] [CrossRef]

6) Miyashita K, Kobayashi H, Koshida S, et al.: Glenohumeral, scapular, and thoracic angles at maximum shoulder external rotation in throwing. Am J Sports Med, 2010, 38: 363-368. [Medline] [CrossRef]

7) Kibler WB: The role of the scapula in athletic shoulder function. Am J Sports Med, 1998, 26: 325-337. [Medline] [CrossRef]

8) Hirashima M, Ohtsuki T: Exploring the mechanism of skilled overarm throwing. Exerc Sport Sci Rev, 2008, 36: 205-211. [Medline] [CrossRef]

9) Kinoshita H, Obata S, Nasu D, et al.: Finger forces in fastball baseball pitching. Hum Mov Sci, 2017, 54: 172-181. [Medline] [CrossRef]

10) Iida H: Little league shoulder. Monthly book. Med Rehabil, 2015, 96: 1-11 (in Japanese).

11) Aranceta-Garza A, Conway BA: Differentiating variations in thumb position from recordings of the surface electromyogram in adults performing static grips, a proof of concept study. Front Bioeng Biotechnol, 2019, 7: 123. [Medline] [CrossRef]

12) Trofa DP, Obana KK, Swindell HW, et al.: Increasing burden of youth baseball elbow injuries in US emergency departments. Orthop J Sports Med, 2019, 7 : 2325967119845636. [Medline]

13) Collins CL, Comstock RD: Epidemiological features of high school baseball injuries in the United States, 2005-2007. Pediatrics, 2008, 121: 1181-1187. [Medline] [CrossRef]

14) Lynch JR, Waitayawinyu T, Hanel DP, et al.: Medial collateral ligament injury in the overhand-throwing athlete. J Hand Surg Am, 2008, 33: 430-437. [Medline] [CrossRef]

15) Sabick MB, Torry MR, Lawton RL, et al.: Valgus torque in youth baseball pitchers: a biomechanical study. J Shoulder Elbow Surg, 2004, 13: 349-355. [Medline] [CrossRef] 